\title{
Sex-related memory recall and talkativeness for emotional stimuli
}

\author{
Benedetto Arnone ${ }^{1}$, Assunta Pompili' , Maria Clotilde Tavares ${ }^{2}$ and Antonella Gasbarri ${ }^{*}$ \\ Department of Biomedical Sciences and Technologies, University of L'Aquila, L'Aquila, Italy \\ 2 Laboratory of Neurosciences and Behavior, Department of Physiological Sciences, Institute of Biology, University of Brasilia, Brasilia, Federal District, Brazil
}

\section{Edited by:}

Carlos Tomaz, University of Brasilia,

Brazil

\section{Reviewed by:}

Cedric Williams, University of Virginia, USA

Alfredo Meneses, Research and

Advanced Studies Center of the

National Polytechnic Institute of

Mexico, Mexico

Carlos Conde, Universidad Industrial de

Santander, Colombia

\section{${ }^{*}$ Correspondence:}

Antonella Gasbarri, Department of Biomedical Sciences and Technologies, University of L'Aquila, Via Vetoio,

Coppito 2, 67100 Coppito, L'Aquila,

Italy.

e-mail:antonella.gasbarri@cc.univaq.it
Recent studies have evidenced an increasing interest in sex-related brain mechanisms and cerebral lateralization subserving emotional memory, language processing, and conversational behavior. We used event-related-potentials (ERP) to examine the influence of sex and hemisphere on brain responses to emotional stimuli. Given that the P300 component of ERP is considered a cognitive neuroelectric phenomenon, we compared left and right hemisphere P300 responses to emotional stimuli in men and women. As indexed by both amplitude and latency measures, emotional stimuli elicited more robust P300 effects in the left hemisphere in women than in men, while a stronger P300 component was elicited in the right hemisphere in men compared to women. Our findings show that the variables of sex and hemisphere interacted significantly to influence the strength of the P300 component to the emotional stimuli. Emotional stimuli were also best recalled when given a long-term, incidental memory test, a fact potentially related to the differential P300 waves at encoding. Moreover, taking into account the sex-related differences in language processing and conversational behavior, in the present study we evaluated possible talkativeness differences between the two genders in the recollection of emotional stimuli. Our data showed that women used a higher number of words, compared to men, to describe both arousal and neutral stories. Moreover, the present results support the view that sex differences in lateralization may not be a general feature of language processing but may be related to the specific condition, such as the emotional content of stimuli.

Keywords: event-related-potential (ERP), P300 wave, language, gender, emotional stimuli, memory, talkativeness

\section{INTRODUCTION}

Emotional events are better memorized than neutral events and in recent years many animal and human studies have yielded evidence for it (Roozendaal, 2000; Arntz et al., 2005; Gasbarri et al., 2005, 2006, 2007, 2008a).

Recent studies have also revealed seemingly large, but previously unsuspected, sex-related influences on this mechanism (Frank and Tomaz, 2000; Cahill, 2006; Gasbarri et al., 2006, 2007; Hofer et al., 2007). For example, the role of the amygdala in emotional memory reveals a different sex-related hemispheric specialization: activity of the right, but not of the left, hemisphere amygdala relates significantly to memory of emotional material in men; conversely, activity of the left, but not the right, hemisphere amygdala relates significantly to memory of emotional material in women (Cahill, 2006). The evidence that each amygdala is likely to modulate information processing in other brain areas (McGaugh, 2000, 2004; Kilpatrick and Cahill, 2003), combined with the fact that amygdalo-cortical projections are almost exclusively ipsilateral, led us to consider the possibility that a sex-related hemispheric lateralization of processing for emotional material may also exist to some degree in cortical regions.

Moreover, despite an absence of sex differences in behavioral performance during the discrimination of emotional (sad and happy) vocal intonation, men evidenced significantly higher activation in the right middle frontal gyrus, while women showed higher activation in the left middle temporal gyrus (Wildgruber et al., 2002). Also, an effect of sex on brain activation during the recognition of fearful faces, despite no sex differences in task performance was reported (Kempton et al., 2009).

Sex differences in cognition are consistently reported: for example, men excel in mental rotation and spatial perception while women perform better in verbal memory tasks, verbal fluency tasks, speed of articulation, episodic memory tasks, and in the utilization of prosodic information (Schirmer et al., 2002; Schirmer and Kotz, 2003). Furthermore, language and reading disorders are reported to occur approximately twice as often in boys than in girls (Flannery et al., 2000), reflecting the sex-related difference in cognitive skills. Sex-related differences in language processing are well known from everyday life, as well as from scientific literature (Hill et al., 2006; Catani et al., 2007). Why females generally perform better on language tasks than males is still unknown (Burman et al., 2008). A common hypothesis attributes this differences to a bilateral contribution of languagerelated cerebral areas in females and a left-hemispheric dominated activation in males (Josse and Tzourio-Mazoyer, 2004; Sommer et al., 2004; Kitazawa and Kansaku, 2005; Ortigue et al., 2005; Hill et al., 2006; Ikezawa et al., 2008). Women might thus use both hemispheres for language functions, while men predominantly 
use the left hemisphere. However, imaging studies reviewed by Sommer et al. (2007) failed to find such a generalized lateralization effect, and reported a left-lateralized activation in both sexes instead. Therefore, sex differences in lateralization may not be a general feature of language processing, but could be related to specific conditions, such as the chosen research method and the heterogeneity of the language tasks used (Hill et al., 2006). This topic is still debated and in the center of attention for many reasons (Clements et al., 2006; Plante et al., 2006). First, there are considerable differences between men and women in the development of language abilities. In fact, when speaking first begins, girls usually articulate better than boys and create longer sentences; perhaps, as a consequence, compared to boys, girls tend to have larger working vocabularies, better use of grammar, and superior reading abilities. Part of this verbal advantage for females survives into adult age, mainly in the domain of use of grammar and verbal fluency (Sommer et al., 2008). Moreover, studies on language disabilities both of severe and mild type reported that boys are affected more frequently than girls (Liederman et al., 2005). Some psychiatric disorders (e.g., autism, attention deficit hyperactivity disorder, schizophrenia) have higher prevalence in males than females (Afifi, 2007), and may be associated with deviations in standard cerebral dominance (Sommer et al., 2007). Additionally, after left cerebral stroke, women appear to recover from aphasia better than men (Pedersen et al., 1995). If a more bilateral language lateralization in women, compared to men, really exists, this could give an explanation for all these observed sex-related differences.

The aim of the present paper is to extend our previous findings, indicating that both sex and cerebral hemisphere constitute important interacting influences on neural correlates of emotion, and emotional memory (Gasbarri et al., 2006, 2007), and to analyze sex-related differences in talkativeness, while describing emotional stimuli.

\section{MATERIALS AND METHODS SUBJECTS}

Sixty-four subjects (32 women and 32 men), mean age 25 ( \pm 4.15), all University of L'Aquila students, viewed pictures from the International Affective Picture System (IAPS).

All the subjects were initially submitted to a screening interview to check for any health problems. All subjects were right-handed, had normal vision and were not suffering from any neurological disorder. Exclusionary criteria included any major medical or psychiatric illness, substance abuse, or history of head injury. All experiments were conducted in accordance with the declaration of Helsinki, and all the procedures were carried out with the adequate understanding of the subjects, who read and signed an informed consent before participating in this research study.

\section{STIMULUS MATERIALS}

The stimulus materials, utilized in this study, consist in emotional stimuli from the IAPS, a set of calibrated picture stimuli widely used in investigating emotion (Lang et al., 1999), previously employed in emotional memory studies (Cahill and McGaugh, 1995; Adolphs et al., 1997; Cahill, 2005; Gasbarri et al., 2005, 2006, 2007, 2008a; Satler et al., 2007).
The set of stimuli consisted in 60 pictures $^{1}$ selected from the IAPS (Lang et al., 1999), according to the valence dimension 20 pleasant, 20 unpleasant, and 20 neutral slides. Pleasant slides were puppies, happy babies, etc., unpleasant slides showed mutilations, wounded people, etc., and neutral slides were common things, such as household objects. More details on this kind of stimulus material can be found in other studies (Cahill and McGaugh, 1995; Adolphs et al., 1997; Frank and Tomaz, 2000; Tomaz et al., 2003; Cahill, 2005; Gasbarri et al., 2005, 2006, 2007, 2008a; Satler et al., 2007).

\section{PROCEDURE}

Participants viewed the IAPS pictures, while seated in a comfortable chair in a sound-attenuated, dimly lit room. After electrode attachment and laboratory adaptation, they were told that a series of emotional slides would be presented and that they should observe each picture the entire time it appeared on the screen, trying not to move their eyes. The entire projection of the slides lasted $10 \mathrm{~min}$; each slide image was presented for $2 \mathrm{~s}$, with the order of the slides randomized for each subject. The trigger was recorded at the beginning and at the end of the stimulus presentation. An $8 \mathrm{~s}$ interval occurred between each trial, during which the screen was completely black except for a small cross at the center of the screen which subjects were instructed to stare at. No cross was shown while the pictures were presented.

At the end of the recording procedures, the participants were asked to judge their personal emotional reactions to the pictures on a scale measuring affective valence. The values included in the scale ranged between 1 (indicating a very unpleasant image) and 10 (indicating a very pleasant image); a score of 5 indicated "not emotional." The subjects were instructed to come back to the laboratory after 10 days, but no mention of a memory test was made. When they came back, subjects performed a free recall task, in which they were asked to recall as many slides as possible, writing down a word or a short sentence describing each one. More details about this kind of stimulus material can be found in previous research (Cahill and McGaugh, 1995; Adolphs et al., 1997; Gasbarri et al., 2005, 2006, 2007, 2008a; Satler et al., 2007).

The free recall was recorded on a portable tape recorder; the number of words utilized in the free recall of positive, negative, and neutral stimuli was counted in female and male subjects, in order to evaluate possible talkativeness differences between the two sexes in the recollection of emotional stimuli.

\section{ERP recording}

EEG signals were recorded at 19 scalp sites (Fp1/Fp2, F3/F4, C3/ C4, P3/P4, O1/O2, F7/F8, T3/T4, T5/T6, Cz, Fz, Pz), according to the International 10/20 System, (Lang et al., 1999) employing actiCap (Brain Products $\mathrm{GmbH}$ ) with active electrodes. Impedance measurement displayed directly at the electrodes and active shielding is implemented; we used the actiCap Control Software (Brain Products $\mathrm{GmbH}$ ).

${ }^{1}$ The IAPS slide numbers were as follows: neutral, 7170, 2200, 2210, 7000, 5510, 6150, 7040, 7050, 7080, 7090, 7100, 7130, 7150, 2190, 7500, 7550, 7560, 7700, 7710; pleasant, 1610, 1710, 1750, 1920, 1602, 2050, 2070, 2080, 2501, 2160, 2260, 2340, $1440,4660,5200,5600,5760,5830,7330,7580$; unpleasant, 9410, 2800, 3000, 3010, $3100,2121,3120,3130,2120,9250,3350,3140,3150,3170,3180,3220,6010,6200$, 6230,9000 . 
Our EEG equipment (BRAINAMP - Brain Products GmbH) includes the Vision Recorder software, which measures specifically with very high precision GND (ground) and REF (reference) electrodes impedance. Impedance of each electrode was checked to insure it was $\leq 5 \mathrm{k} \Omega$. Horizontal and vertical eye movements were monitored with a bipolar recording from electrodes at left and right outer canthi. The EEG from each electrode site was digitalized at $250 \mathrm{~Hz}$. To further reduce highfrequency noise, the averaged visual evoked potentials were filtered at $0.01 \mathrm{~Hz}(24 \mathrm{~dB} /$ octave) and $30 \mathrm{~Hz}(24 \mathrm{~dB} /$ octave $)$ with $50 \mathrm{~Hz}$ notch filter.

Visual evoked potentials were stored for offline averaging using Brain Vision Analyzer (Version 1.05.0001 - Brain Products GmbH). Epochs of averaging were $100 \mathrm{~ms}$ prior the stimulus onset and $1000 \mathrm{~ms}$ after stimulus onset.

Computerized artifact rejection was performed prior to signal averaging in order to discard epochs in which deviation in eye position, blinks, or amplifier blocking occurred. We used the difference criterion with the maximal allowed absolute difference of two values in the segment of $250.00 \mu \mathrm{V}$.

On average, about $18 \%$ of the trials were rejected for violating these artifact criteria. We considered "not valid" trials of the subjects who interrupted the EEG recordings for personal reasons and trials in which deviation in eye position, blinks, or amplifier blocking occurred during the averaging.

\section{WORD COUNT}

In order to evaluate possible talkativeness differences between the two sexes in the recollection of emotional stimuli, we counted the number of words that men and women used when they were submitted to a declarative memory test, using IAPS slides as emotional stimuli. To this aim, research assistants listened to audiorecordings of the task and tallied the words with an electronic counter. According to other studies (Wardle et al., 2011), non-word utterances such as "umm," "uhh," “err," and "ehh" were included in the count. The decision to include non-word utterances was made on the basis that these "filled pauses" indicate intent or urge to speak, and thus should be treated differently than silence. Indeed, in previous research, filled pauses have been particularly sensitive to drug effects (Epstein et al., 2010; Marrone et al., 2010), suggesting that they do differ qualitatively from unfilled pauses. A 30-s segment of the task of each subject was recounted by a "standard" rater (the first author). If his count of the sample differed by more than two words from the count given by a research assistant, the entire recording was recounted. This procedure resulted in less than $1 \%$ of individual tasks needing to be recounted, and none of these final counts were discrepant from the original counts by more than 10 words.

\section{STATISTICAL ANALYSIS}

Data obtained were analyzed using analyses of variance (ANOVA). The analysis of event-related-potential (ERP) parameters, P300 amplitude, and latency was conducted separately. All trials that violated the artifact criteria were rejected. Differences between groups were tested using Tuckey's test.

Statistical significance was set at $p<0.05$. All data are presented as means \pm SEM.

\section{RESULTS \\ EMOTIONAL REACTIONS}

The personal emotional responses to the IAPS slides reliably discriminated neutral from emotional pictures, and confirmed differences in affective content between the slide categories. Unpleasant pictures were judged significantly less pleasant than the neutral pictures which, in turn, were rated less positively than pleasant pictures.

The three stimulus contents were distinct and representative of affect type: mean valence (nine-point scales, pleasant high) for pleasant pictures was $7.11( \pm 1.34)$ in men and 7.65 $( \pm 0.89)$ in women. Mean valence for unpleasant pictures was $2.74( \pm 1.26)$ in men and $2.39( \pm 1.35)$ in women. Mean valence for neutral pictures was $5.20( \pm 0.86)$ in men and $5.04( \pm 1.17)$ in women.

\section{EVOKED POTENTIALS}

The P300 window was set at $300-450 \mathrm{~ms}$ after stimulus onset. P300 was quantified within each average waveform as the largest positive deflection in that epoch. Both P300 amplitude and latency data were computed. Grand-average ERPs in response to unpleasant, pleasant and neutral stimuli are presented in Figure 1.

\section{P300 amplitude}

The P300 amplitude was determined for F3/F4, and P3/P4 electrode sites in both men and women (Figure 2). All data were analyzed using ANOVA followed by Tuckey's test.

Frontal sites. At site F3, women showed a P300 amplitude in response to unpleasant slides that was significantly higher compared to both pleasant $\left[F(1,62)=35.25 ;{ }^{*} p<0.0001\right]$ and neutral slides $\left[F(1,62)=156.02 ;{ }^{* *} p<0.001\right]$. Moreover, in women the P300 amplitude in response to unpleasant slides was significantly higher compared to men $[F(1,62)=40.89 ; \bullet p<0.0001]$.

In men, P300 amplitude in response to unpleasant slides was significant higher at site $\mathrm{F} 4$ compared to $\mathrm{F} 3[F(1,62)=9.40$; $\left.{ }^{*} p<0.003\right]$, while in women it was significantly higher at site F3 compared to $\mathrm{F} 4[F(1,62)=22.26 ; \otimes<0.0001]$.

The evaluation of amplitude in response to pleasant and neutral slides did not reveal any significantly difference between males and females at either F3 or F4 electrode sites.

Parietal sites. At site P3, women showed a P300 amplitude in response to unpleasant slides that was significantly higher compared to either pleasant $\left[F(1,62)=14.491 ;{ }^{*} p<0.0001\right]$ and neutral slides $\left[F(1,62)=107.842 ;{ }^{* *} p<0.001\right]$. Moreover, in women the P300 amplitude in response to unpleasant slides was significantly higher compared to men $[F(1,62)=6.532$; $\bullet p<0.013]$.

In men, P300 amplitude in response to unpleasant slides was significantly higher at site $\mathrm{P} 4$ compared to $\mathrm{P} 3[F(1,62)=9.409$; $\left.{ }^{*} p<0.003\right]$, while in women it was significantly higher at site P3 compared to $\mathrm{P} 4[F(1,62)=7.867 ; p<0.012]$.

The evaluation of amplitude in response to pleasant and neutral slides did not reveal any significant difference between males and females at either P3 or P4 electrode sites. 

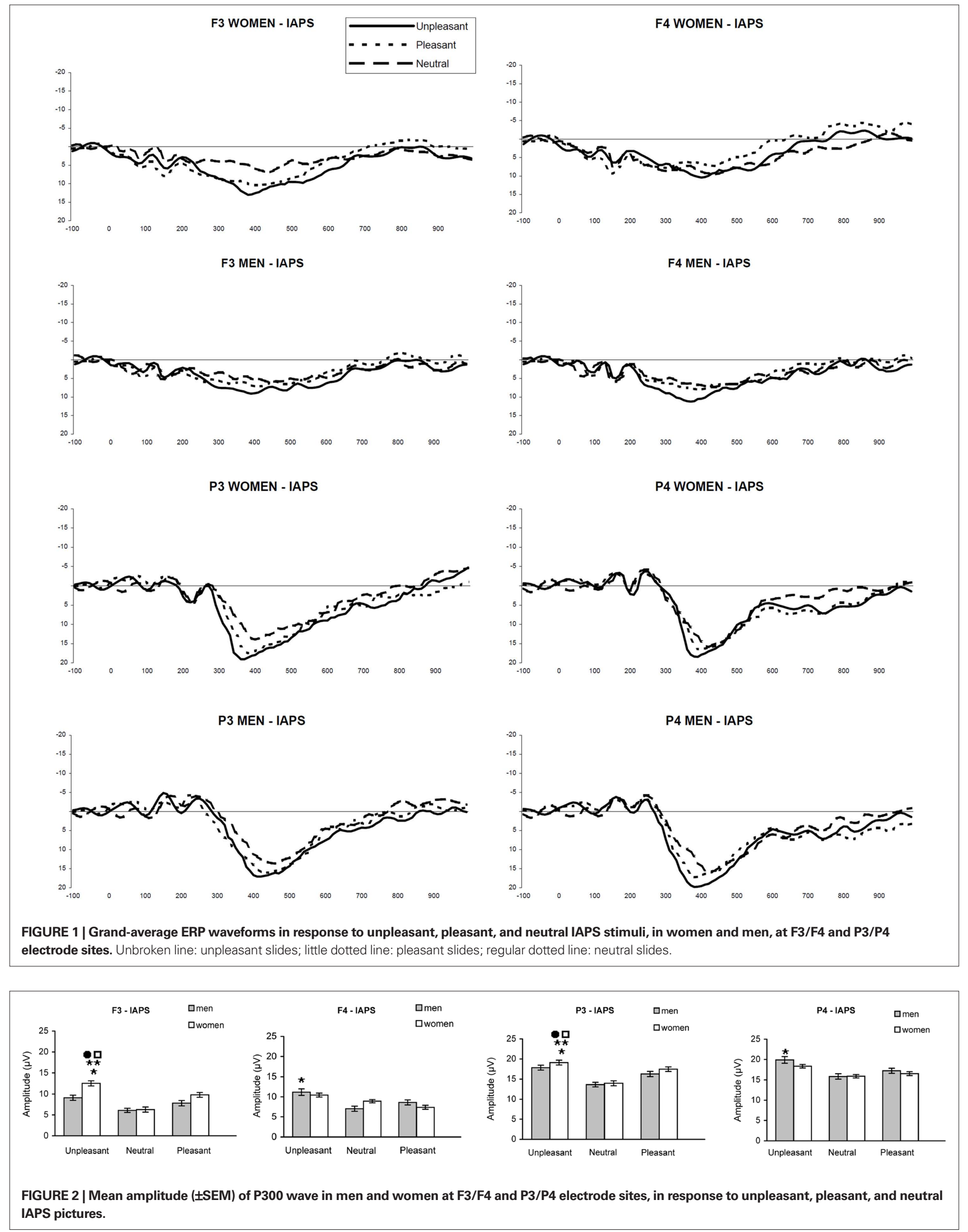

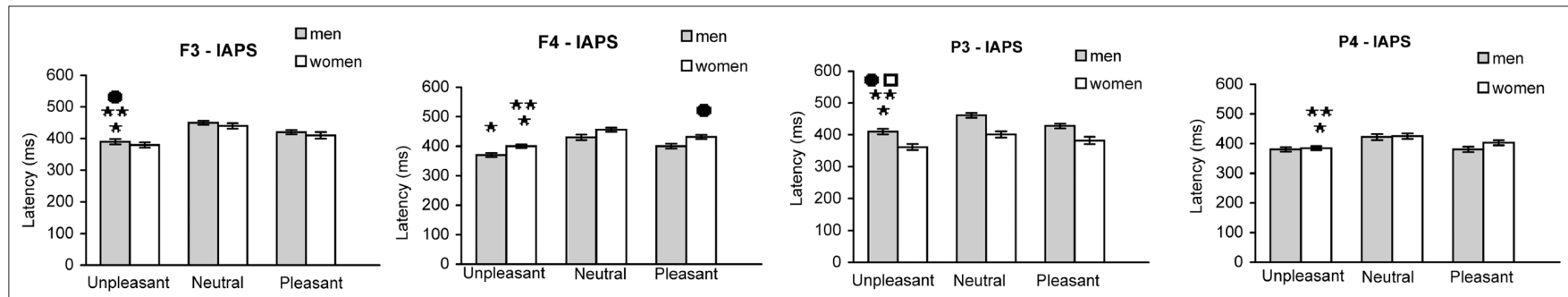

FIGURE 3 | Mean latency ( \pm SEM) of P300 wave in men and women at F3/F4 and P3/P4 electrode sites, in response to unpleasant, pleasant, and neutral IAPS pictures.

\section{P300 latency}

The P300 latency was determined for P3/4, and F3/4 electrode sites in both men and women (Figure 3). All data were analyzed using ANOVA followed by Tuckey's test.

Frontal sites. At site F3, the P300 latency in women after the presentation of unpleasant slides was significantly shorter compared to both pleasant $\left[F(1,62)=15.941 ;{ }^{*} p<0.0001\right]$ and neutral slides $\left[F(1,62)=84.071 ;{ }^{* *} p<0.0001\right]$. Furthermore, latency at site F3 was significantly longer in men than in women $[F(1,62)=3.982$; $\bullet p<0.005$ ] in response to unpleasant slides. Indeed, the latency in response to unpleasant slides was significantly longer at F3 than at F4 electrode site in men $\left[F(1,62)=11.108 ;{ }^{*} p<0.001\right]$, but significantly longer at $\mathrm{F} 4$ than at $\mathrm{F} 3$ in women $\left[F(1,62)=17.15{ }^{\star}{ }^{\star} p<0.01\right]$.

At site $\mathrm{F} 4$ the $\mathrm{P} 300$ latency in response to the unpleasant slides was significantly longer in women compared to men $[F(1,62)=25.710$; $\left.{ }^{* *} p<0.0001\right]$; moreover, the P300 latency in response to the pleasant slides was significantly longer in women compared to men $[F(1,62)=6.160 ; \bullet p<0.016]$.

The evaluation of latency in response to pleasant and neutral slides did not reveal any significant difference between males and females at either F3 or F4 electrode sites.

Parietal sites. At site P3, in men, the P300 latency after the presentation of unpleasant slides was significantly shorter compared to both pleasant $\left[F(1,62)=6.215 ;{ }^{\star} p<0.015\right]$ and neutral slides $\left[F(1,62)=57.57 ;{ }^{* *} p<0.0001\right]$. Furthermore, latency at site P3 was significantly longer in men than in women in response to unpleasant slides $[F(1,62)=44.50 ; \bullet p<0.001]$. Indeed, the latency in response to unpleasant slides was significantly longer at $\mathrm{P} 3$ than at P4 electrode site in men $[F(1,62)=23.09 ; p<0.0001]$, but significantly longer at $\mathrm{P} 4$ than at $\mathrm{P} 3$ in women $[F(1,62)=9.54$; ${ }^{*} p<0.003$ ].

Finally, at site P4 the P300 latency in response to the unpleasant slides was significantly longer in women compared to men $\left[F(1,62)=21.10 ;{ }^{* *} p<0.003\right]$.

The evaluation of latency in response to pleasant and neutral slides did not reveal any significant difference between males and females at either P3 or P4 electrode sites.

\section{MEMORY}

Free recall for the IAPS, evaluated on the basis of the number of pictures recalled, revealed that emotional content influenced memory both in men and women.
In fact, men recalled $7.34( \pm 1.78)$ unpleasant, $5.3( \pm 1.51)$ pleasant, and $2.45( \pm 1.52)$ neutral pictures; similarly, women recalled 8.3 $( \pm 2.16)$ unpleasant, $4.9( \pm 1.83)$ pleasant, and $1.87( \pm 1.28)$ neutral pictures.

The evaluation of memory for the IAPS slides showed that men recalled significantly more unpleasant slides compared to both pleasant $\left(\left[F(1,62)=24.063 ;{ }^{*} p<0.0001\right]\right)$ and neutral slides $\left[F(1,62)=139.585 ;{ }^{* *} p<0.0001\right]$ (Figure 4); analogously, women recalled a significantly higher number of unpleasant than pleasant $\left[F(1,62)=46.114 ;{ }^{\star} p<0.001\right]$ and neutral $[F(1,62)=209.344$; $\left.{ }^{\star *} p<0.0001\right]$ slides.

The number of pleasant slides recalled by women and men was higher compared to neutral, even though this difference was statistically significant in men $[F(1,62)=56.33, v p<0.012]$, but not in women $[F(1,62)=2.59, p<0.112$ n.s.; Figure 4].

The comparison between men and women revealed that females recalled a higher number of slides compared to males, even though the difference was statistically significant for the unpleasant $[F(1,62)=8.62, p<0.005]$, but not for the pleasant $[F(1,62)=0.93, p<0.338$ n.s. $]$ and neutral $[F(1,62)=2.54$, $p<0.116$ n.s.] slides.

\section{TALKATIVENESS}

In the free recall, the quantification of the number of words utilized by the subjects evidenced that women used 99.4 $( \pm 21.41)$ words to describe the unpleasant, $73.1( \pm 13.36)$ for the description of the pleasant, and 46.8 ( \pm 15.62$)$ for the neutral slides. Our results show that female subjects utilized a statistically significant higher number of words to describe the unpleasant slides, compared to both pleasant $[F(1,62)=35.53$; $v p<0.01]$ and neutral $[F(1,62)=132.28 ; v v p<0,01]$ pictures; moreover, they used a statistically significant higher number of words to describe the pleasant compared to neutral slides $\left[F(1,62)=56.33 ;{ }^{* *} p<0,1\right]$.

Men utilized $73.2( \pm 7.93)$ words to describe the unpleasant slides, $51.9( \pm 6.68)$ to describe the pleasant, and $46.5( \pm 15.44)$ to describe the neutral (Figure 5). Our findings reveal that male subjects utilized a statistically significant higher number of words to describe the unpleasant slides, compared to both pleasant $[F(1,62)=147.62 ; v v p<0.001]$, and neutral $[F(1,62)=78.68$; $v \vee v p<0.01]$; moreover, they used a higher number of words to describe the pleasant compared to neutral $[F(1,62)=2.59$; $p<0.112$ n.s.], even though the difference is not statistically significant. 


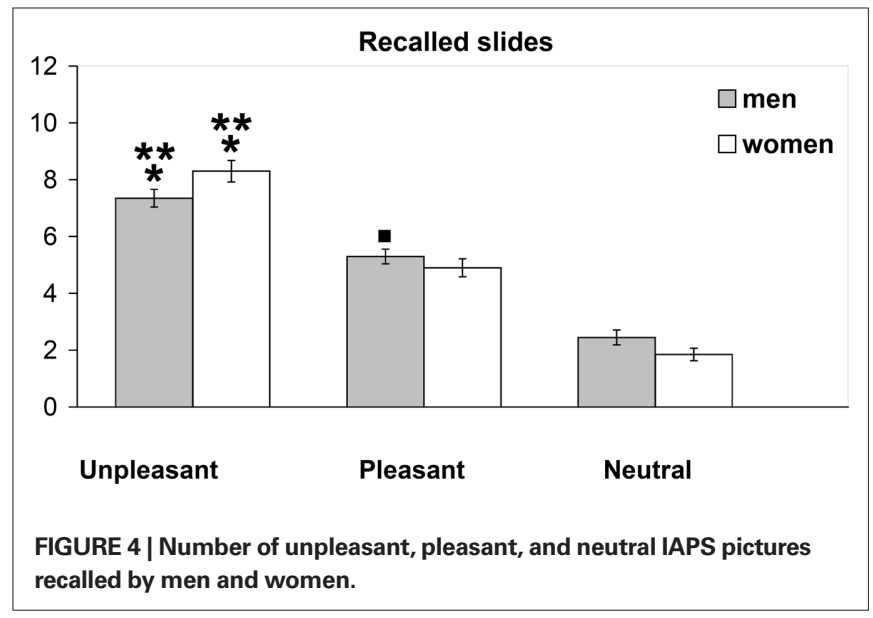

The comparative evaluation of the number of words utilized by men and women showed that women used a higher number of words compared to men to describe both the unpleasant $\left[F(1,62)=40.98 ;^{*} p<0.001\right]$, and pleasant pictures $\left[F(1,62)=69.01 ;^{* *} p<0.001\right]$; regarding the neutral slides, even though women used a higher number of words, compared to men, to describe them, the difference was not statistically significant $[F(1,62)=0.011 ; p<0.917$ n.s. $]$.

\section{DISCUSSION}

Functional sex-related differences have been shown in brain correlates of emotional (Gasbarri et al., 2008b,c) and facial processing (Killgore and Yurgelun-Todd, 2001), working memory (Speck et al., 2000), auditory (Salmelin et al., 1999; Hulten et al., 2010) and language processing (Shaywitz et al., 1995; Pugh et al., 1996).

The present findings indicate that gender is a crucial variable in understanding cerebral hemisphere function, particularly in relation to emotional conditions, confirming that men and women differ in brain activation during cognitive tasks. In addition, we clearly confirm and extend our recent studies based on ERP, evaluating whether a sex-related hemispheric lateralization of electrical potentials elicited by emotional stimuli exists (Gasbarri et al., 2006, 2007, 2008a).

It is well known that P300 latency is considered a metric of stimulus classification speed, with shorter latencies thought to reflect superior cognitive performance (Duncan et al., 2009) and P300 latency and amplitude are negatively correlated (Polich, 2003).

As indexed by both amplitude and latency measures, the present results showing that emotional stimuli elicited a stronger P300 in women than in men, in the left hemisphere, and a stronger P300 in men than in women, in the right hemisphere, are in agreement with brain imaging studies indicating greater left hemisphere amygdala participation in processing memory of emotionally arousing material in women, but better right hemisphere amygdala processing into memory of the same material in men (Canli et al., 2002; Cahill, 2005, 2006, 2010; Andreano and Cahill, 2010).

Moreover, our data showing more robust right hemisphere P300 effects in men, and more robust left hemisphere P300 effects in women to arousing stimuli, reveal that the emotional slides were also better remembered, suggesting that the P300 effects could be related to the enhancement of memory.

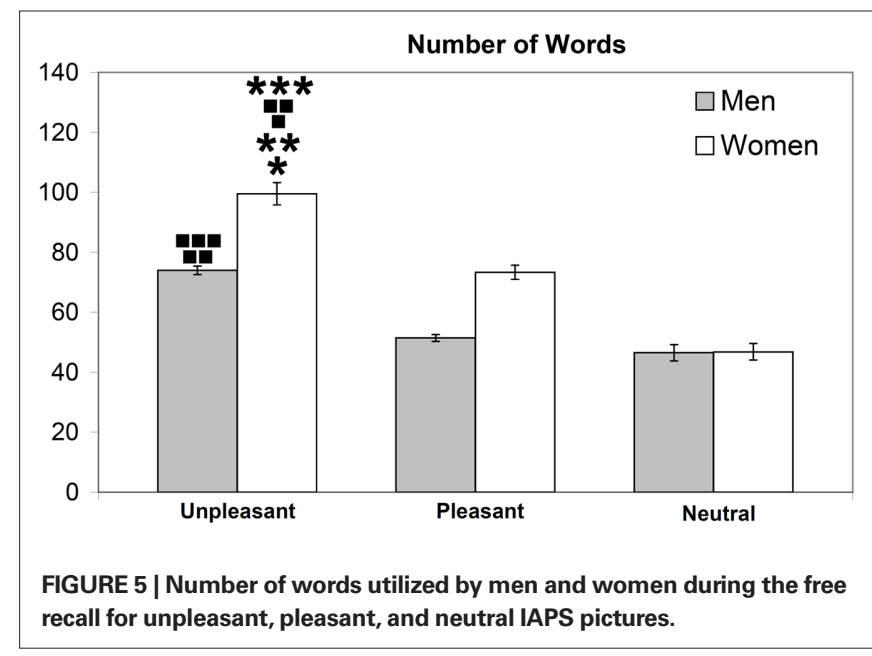

In our study, the higher reactivity to unpleasant stimuli of women, compared to men, is in agreement with other research showing that females are more reactive to emotional unpleasant stimuli, particularly those that are threatening or traumatic (Whittle et al., 2011). Greater female reactivity has been found in the domains of self-report (Lang et al., 1993), behavioral response (Vigil, 2009), and physiological responding (Lithari et al., 2010), although some inconsistent findings were reported (Schienle et al., 2005; Fugate et al., 2009).

Many research works have revealed a gender-related dimorphism during the processing of emotional stimuli (Schirmer et al., 2002; Brebner, 2003; Campanella et al., 2004; Montagne et al., 2005; Scholten et al., 2005). Among these studies, one of the most noticeable observation is that men, compared to women, are less capable of labeling negative emotions ( Li et al., 2008). Early reports showed that males are less accurate in recognizing emotions from faces, in particular in recognizing negative emotions such as fear, disgust, and sadness (Hall, 1978; Miura, 1993), and more recent studies, related to psychosocial aspects of depression, suggested that interpersonal communications through non-verbal emotional cues are more pronounced in women than in men (Harris, 2001; Campanella et al., 2004). Moreover, when asked to identify facial affects, healthy males had lower accuracy scores than healthy females in recognizing negative emotions, and the performances of male schizophrenic patients were impaired compared to female patients (Scholten et al., 2005). Similarly, women were more accurate in labeling negative emotions and identifying negative facial expressions, compared to men (Montagne et al., 2005). The advantage of women, compared to men, in identifying negative emotions, could be attributed to the reduced sensitivity to emotionally negative stimuli of men, compared to women, since it was shown that the same emotionally negative pictures activated more neural substrates as well as greater cerebral activation values (e.g., in amygdala) in females than in males (Wrase et al., 2003; Hofer et al., 2006; Li et al., 2008). These results evidence that women are more susceptible to negative emotions in life settings, which may be one important mechanism underlying their higher prevalence of affective disturbances, compared to men (Yuan et al., 2009). 
It is widely recognized that the female brain has tremendous unique aptitudes outstanding verbal fluency, the ability to connect deeply in friendship, to read faces and tone of voice for emotions (Brizendine, 2006).

In the present study, the evaluation of the number of words utilized by male and female subjects which we counted during the free recall of emotional and neutral stimuli, showed that in both emotional and neutral pictures, women used a higher number of words compared to men. Sex-related differences in language processing and conversational behavior have long been an issue of scientific and also of public interest (Litosseliti, 2006; Mehl et al., 2007). Sexual dimorphism of cognitive ability has consistently been shown to occur in two domains: the former is represented by visuo-spatial ability (such as spatial perception, mental rotation, and mathematical tasks), and the latter includes tasks of verbal memory, verbal fluency, and speed of articulation. While men excel in visual-spatial ability skills, women outperform men in verbal fluency and episodic memory tasks, as well as in the use of prosodic information (Schirmer et al., 2002; Schirmer and Kotz, 2003; Bell et al., 2006).

The biological explanation for gender differences in language use hypothesizes that sex-related differences have resulted from evolutionary pressures for men to be more aggressive and self-assertive, and for women to be more nurturing and affiliative (Lippa, 2005; Luxen, 2005; Pellegrini and Archer, 2005; Anderson et al., 2006; Leaper and Ayres, 2007). A hypothesis underlying this view is that the brain of men and women tend to differ in its organization and functioning. Indeed, it was proposed that the female brain performs better in language ability (Andersen, 2006). This view is supported by studies indicating a slight advantage for girls over boys in language development and ability. There are also some studies suggesting average sex differences in brain lateralization (Gleason, 2002).

The cerebral substrate of the sex-related differences in cognition is actually still unclear. The most common hypothesis attributes sex-related differences in language processing to a left-hemispheric dominated activation in men, and a bilateral contribution of language-related brain areas in women (Josse and Tzourio-Mazoyer, 2004). Thus, males might predominantly use the left hemisphere for language functions, while women use both hemispheres. A more bilateral pattern of language representation could result in better verbal skills, while visuo-spatial processing would be inferior in subjects with bilateral language representation. Therefore, the female deficit in spatial performance is thought to arise from competition between verbal and spatial functions in the right hemisphere (Sommer et al., 2004). Many findings support this theory that sex differences in cognition result from more bilateral representation of language functions in women than in men. For example, it was showed that female stroke patients, compared to males, exhibited verbal impairment less frequently after lesions of the left hemisphere; in addition, a less pronounced asymmetry of the temporal planum in women, compared to men, was also reported (Foundas et al., 2002; Sommer et al., 2004).

Sex differences in conversational behavior and language processing have long been an issue of scientific and also public interest. Moreover, behavioral and functional imaging studies evidenced better performances of women, compared to men, in executive speech tasks (Weiss et al., 2006); in addition, differences in the influence of cognitive factors, such as speed of information processing, word knowledge, and long-term memory on verbal fluency factors were also reported (Weiss et al., 2006).

The popular stereotype that women are more talkativeness than men is often considered a scientific evidence (Brizendine, 2006), even though conflicting data still exist (Mehl et al., 2007), and many imaging studies failed to find such a generalized lateralization effect, reporting a left-lateralized activation in both sexes instead (Hill et al., 2006). This implies that the putative sex difference in language lateralization may be evidenced only with particular, as yet not defined, language tasks.

It is possible to hypothesized that part of the well known controversy about whether women speak more than men (Leaper and Ayres, 2007) may be related to the manner in which the speech is elicited, and the kind of task utilized (Wardle et al., 2011).

Most of the studies held gender constant, which might also contribute to different effects in same vs. opposite sex dyads. Future studies might also consider systematically varying the gender of the experimenter. Therefore, the hypothesis that differences in language lateralization underlie the general sex differences in cognitive performance has still to be confirmed, and the neuronal basis for these cognitive sex differences remains elusive.

Research into activation effects of ovarian hormones demonstrated that speech articulation and verbal fluency are enhanced at the high hormonal phases of the menstrual cycle (Wadnerkar et al., 2006). Many sex differences in language, that were once explained by testosterone-mediated effects alone, are now supposed to be the result of active differentiation in both sexes, i.e., feminisation in females and masculinisation in males (Whiteside et al., 2004). Ovarian estrogen influences the organization of many neurobehavioral systems in both non-humans and human species (Bimonte and Denenberg, 1999), and hormonal changes across the menstrual cycle affect several activational parameters at the neuroanatomical, neurofunctional, and behavioral levels (Sanders and Wenmoth, 1998; Rudick and Woolley, 2001; Sandstrom and Williams, 2001; Gasbarri et al., 2008c; Ossewaarde et al., 2010). Studies evaluating different tests of cognition and behavior, including reports of motor and perceptual skills and functional laterality in perception, showed that performance is systematically altered as a function of hormonal fluctuations during the menstrual cycle (Maki et al., 2002). Overall, the literature indicates that some abilities are positively, and others negatively influenced, during particular phases of the menstrual cycle corresponding to high levels of circulating estrogen (Hausmann et al., 2002) and, in some cases, also to progesterone (Whiteside et al., 2004).

However, much remains unclear about the organization and co-ordination of speech production systems as a function of activation by ovarian hormones across the menstrual cycle (Kitazawa and Kansaku, 2005).

The results of the current study support the view that sex differences in lateralization may not be a general feature of language processing but may be related to the specific condition, such as the emotional content of the stimuli used in the present research.

Moreover, taking into account that many data suggest that significantly different patterns of activation exist between men and women in different cognitive tasks and in various paradigms, the 
present study reinforces the fact that gender matching is essential in functional studies, and supports the idea of exploring male and female populations as distinct groups.

In conclusion, according to previous studies indicating that men and women process emotional stimuli differently, our findings suggest the existence of gender-related neural responses to emotional stimuli, and highlight the neurobiological basis of mechanisms that

\section{REFERENCES}

Adolphs, R., Cahill, L., Schul, R., and Babinsky, R. (1997). Impaired declarative memory for emotional material following bilateral amygdala damage in humans. Learn. Mem. 4, 291-300.

Afifi, M. (2007).Gender differences in mental health.Singapore Med. J.48,385-391.

Andersen, P. A. (2006). Sex Differences and Similarities in Communication the Evolution of Biological Sex Differences in Communication. Mahwah, NJ: Lawrence Erlbaum.

Anderson, A. K., Yamaguchi, Y., Grabski, W., and Lacka, D. (2006). Emotional memories are not all created equal: evidence for selective memory enhancement. Learn. Mem. 13, 711-718.

Andreano, J. M., and Cahill, L. (2010). Menstrual cycle modulation of medial temporal activity evoked by negative emotion. Neuroimage 53, 1286-1293.

Arntz, A., De Groot, C., and Kindt, M. (2005). Emotional memory is perceptual.J. Behav. Ther. Exp. Psychiatry. $36,19-34$.

Bell, E. C., Willson, M. C., Wilman, A. H., Dave, S., and Silverstone, P. H. (2006). Males and females differ in brain activation during cognitive tasks. Neuroimage 30, 529-538.

Bimonte, H. A., and Denenberg, V. H. (1999). Estradiol facilitates performance as working memory load increases. Psychoneuroendocrinology 24, 161-173.

Brebner, J. (2003). Gender and emotions. Pers. Individ. Dif. 34, 387-394.

Brizendine, L. (2006). The Female Brain. New York: Morgan Road Books.

Burman, D. D., Bitan, T., and Booth, J. R. (2008). Sex differences in neural processing of language among children. Neuropsychologia 46, 1349-1362.

Cahill, L. (2005). His brain, her brain. Sci. Am. 292, 40-47.

Cahill, L. (2006). Why sex matters for neuroscience. Nat. Rev. Neurosci. 7 , 477-484.

Cahill, L. (2010). Sex influences on brain and emotional memory: the burden of proof has shifted. Prog. Brain Res. 186, 29-40.

Cahill, L., and McGaugh, J. L. (1995). A novel demonstration of enhanced memory associated with emotional arousal. Conscious. Cogn. 4, 410-421.

Campanella, S., Rossignol, M., Mejias, S., Joassin, F., Maurage, P., Debatisse,
D., Bruyer, R., Crommelinck, M., and Guerit, J. M. (2004). Human gender differences in an emotional visual oddball task: an event-related potentials study. Neurosci. Lett. 367, 14-18.

Canli, T., Desmond, J. E., Zhao, Z., and Gabrieli,J.D. (2002). Sex differences in the neural basis of emotional memories. Proc. Natl. Acad. Sci. U.S.A. 99, 10789-10794.

Catani,M.,Allin,M.P.,Husain,M.,Pugliese, L., Mesulam, M. M., Murray, R. M., and Jones, D. K. (2007). Symmetries in human brain language pathways correlate with verbal recall. Proc. Natl. Acad. Sci. U.S.A. 104, 17163-17168.

Clements, A. M., Rimrodt, S. L., Abel, J. R., Blankner, J. G., Mostofsky, S. H., Pekar, J. J., Denckla, M. B., and Cutting, L. E. (2006). Sex differences in cerebral laterality of language and visuospatial processing. Brain Lang. 98, 150-158.

Duncan, C. C., Barry, R. J., Connolly, J. F., Fischer, C., Michie, P. T., Naatanen, R., Polich, J., Reinvang, I., and Van Petten, C. (2009). Event-related potentials in clinical research: guidelines for eliciting, recording, and quantifying mismatch negativity, P300, and N400. Clin. Neurophysiol. 120, 1883-1908.

Epstein, D. H., Marrone, G. F., Heishman, S. J., Schmittner, J., and Preston, K. L. (2010). Tobacco, cocaine, and heroin: craving and use during daily life. Addict. Behav. 35, 318-324.

Flannery, K. A., Liederman, J., Daly, L., and Schultz, J. (2000). Male prevalence for reading disability is found in a large sample of black and white children free from ascertainment bias. J. Int. Neuropsychol. Soc. 6, 433-442. Hanna-Pladdy, B. (2002). Variability in the anatomy of the planum temporale and posterior ascending ramus: do right- and left handers differ? Brain Lang. 83, 403-424.

Frank, J. E., and Tomaz, C. (2000). Enhancement of declarative memory associated with emotional content in a Brazilian sample. Braz. J. Med. Biol. Res. 33, 1483-1489.

Fugate,J.M. B., Gouzoules, H., and Barrett, L. F. (2009). Separating production from perception: perceiver-based explanations for sex differences in emotion. Behav. Brain Sci. 32, 394.

Gasbarri, A., Arnone, B., Pompili, A., Cifariello, A., Marini, C., Tavares, M.
Foundas, A. L., Leonard, C. M., and

may be underlying the gender disparity of neuropsychiatric diseases, such as mood disorders. In addition, considering that much remains unclear about the organization and co-ordination of speech production systems, as a function of activation by ovarian hormones across the menstrual cycle, future studies should take into account menstrual cycle stage and gonadal steroid hormone levels in the female subjects.

C., and Tomaz, C. (2008a). Emotional memory and migraine: effects of amitriptyline and sex related difference. Behav. Brain Res. 189, 220-225.

Gasbarri, A., Pompili, A., D’onofrio, A., Abreu, C. T., and Tavares, M. C. (2008b). Working memory for emotional facial expressions: role of estrogen in humans and non-human primates. Rev. Neurosci. 19, 129-148.

Gasbarri, A., Pompili, A., D’onofrio, A. Cifariello, A., Tavares, M. C., and Tomaz, C. (2008c). Working memory for emotional facial expressions: role of the estrogen in young women. Psychoneuroendocrinology 33,964-972.

Gasbarri, A., Arnone, B., Pompili, A., Marchetti, A., Pacitti, F., Calil, S. S., Pacitti, C., Tavares, M. C., and Tomaz, C. (2006). Sex-related lateralized effect of emotional content on declarative memory: an event related potential study. Behav. Brain Res. 168, 177-184.

Gasbarri, A., Arnone, B., Pompili, A., Pacitti, F., Pacitti, C., and Cahill, L. (2007). Sex-related hemispheric lateralization of electrical potentials evoked by arousing negative stimuli. Brain Res. 1138, 178-186.

Gasbarri, A., Pompili, A., Arnone, B., D'onofrio,A., Marchetti, A., Tavares, M C., and Tomaz, C. (2005). Declarative memory retention and emotional stimuli. A study of an Italian sample. Funct. Neurol. 20, 157-162.

Gleason, G. B., and Ely, R. (2002). “Gender differences in language development," in Biology, Society, and Behavior: The Development of Sex Differences in Cognition. Advances in Applied Developmental Psychology, eds A. McGillicuddy-De Lisi and R. De Lisi (Westport, CT: Ablex Publishing), 21, 127-154.

Hall, J.A. (1978). Gender effects in decoding nonverbal cues. Psychol. Bull. 85, 845-857.

Harris, T. (2001). Recent developments in understanding the psychosocial aspects of depression. Br. Med. Bull. 57, 17-32.

Hausmann, M., Becker, C., Gather, U., and Gunturkun, O. (2002). Functional cerebral asymmetries during the menstrual cycle: a cross-sectional and longitudinal analysis. Neuropsychologia 40, 808-816.

Hill, H., Ott, F., Herbert, C., and Weisbrod, M. (2006). Response execution in lexical decision tasks obscures sexspecific lateralization effects in language processing: evidence from event-related potential measures during word reading. Cereb. Cortex 16, 978-989.

Hofer, A., Siedentopf, C. M., Ischebeck, A., Rettenbacher, M. A., Verius, M., Felber, S., and Fleischhacker, W. W. (2006). Gender differences in regional cerebral activity during the perception of emotion: a functional MRI study. Neuroimage 32, 854-862.

Hofer, A., Siedentopf, C. M., Ischebeck, A., Rettenbacher, M. A., Verius, M., Felber, S., and Wolfgang Fleischhacker, W. (2007). Sex differences in brain activation patterns during processing of positively and negatively valenced emotional words. Psychol. Med.37, 109-119.

Hulten, A., Laaksonen, H., Vihla, M., Laine, M., and Salmelin, R. (2010). Modulation of brain activity after learning predicts long-term memory for words. J. Neurosci. 30, 15160-15164.

Ikezawa, S., Nakagome, K., Mimura, M. Shinoda, J., Itoh, K., Homma, I., and Kamijima, K. (2008). Gender differences in lateralization of mismatch negativity in dichotic listening tasks. Int. J. Psychophysiol. 68, 41-50.

Josse, G., and Tzourio-Mazoyer, N. (2004). Hemispheric specialization for language. Brain Res. Brain Res. Rev. 44, $1-12$.

Kempton, M. J., Haldane, M., Jogia, J., Grasby, P.M., Collier, D., and Frangou, S. (2009). Dissociable brain structural changes associated with predisposition, resilience, and disease expression in bipolar disorder. J. Neurosci. 29, 10863-10868.

Killgore, W. D., and Yurgelun-Todd, D. A. (2001). Sex differences in amygdala activation during the perception of facial affect. Neuroreport 12, 2543-2547.

Kilpatrick, L., and Cahill, L. (2003). Amygdala modulation of parahippocampal and frontal regions during emotionally influenced memory storage. Neuroimage 20, 2091-2099.

Kitazawa, S., and Kansaku, K. (2005). Sex difference in language lateralization may be task-dependent. Brain 128, E30. [author reply E31].

Lang, P. J., Bradley, M. M., and Cuthbert, B. N. (1999). International Affective Picture System (IAPS): Technical 
Manual and Affective Ratings. Gainesville, FL: University of Florida.

Lang, P. J., Greenwald, M. K., Bradley, M. M., and Hamm, A. O. (1993). Looking at pictures: affective, facial, visceral, and behavioral reactions. Psychophysiology 30, 261-273.

Leaper, C., and Ayres, M. M. (2007). A meta-analytic review of gender variations in adults' language use: talkativeness, affiliative speech, and assertive speech. Pers. Soc. Psychol. Rev. 11, 328-363.

Li, H., Yuan, J., and Lin, C. (2008). The neural mechanism underlying the female advantage in identifying negative emotions: an event-related potential study. Neuroimage 40, 1921-1929.

Liederman, J., Kantrowitz, L., and Flannery, K. (2005). Male vulnerability to reading disability is not likely to be a myth: a call for new data. J. Learn Disabil. 38, 109-129.

Lippa, R.-A. (2005). Gender, Nature, and Nurture. Mahwah, NJ: Lawrence Erlbaum.

Lithari, C., Frantzidis, C. A., Papadelis, C., Vivas, A. B., Klados, M. A., KourtidouPapadeli, C., Pappas, C., Ioannides, A. A., and Bamidis, P. D. (2010). Are females more responsive to emotional stimuli? A neurophysiological study across arousal and valence dimensions. Brain Topogr. 23, 27-40.

Litosseliti, L. (2006). Gender and Language: Theory and Practice. London: Arnold.

Luxen, M. F. (2005). Gender differences in dominance and affiliation during a demanding interaction. J. Psychol. 139, 331-347.

Maki, P. M., Rich, J. B., and Rosenbaum, R. S. (2002). Implicit memory varies across the menstrual cycle: estrogen effects in young women. Neuropsychologia 40, 518-529.

Marrone, G. F., Pardo, J. S., Krauss, R. M., and Hart, C. L. (2010). Amphetamine analogs methamphetamine and 3 , 4-methylenedioxymethamphetamine (MDMA) differentially affect speech. Psychopharmacology (Berl.) 208, 169-177.

McGaugh, J. L. (2000). Memory - a century of consolidation. Science 287, 248-251.

McGaugh, J. L. (2004). The amygdala modulates the consolidation of memories of emotionally arousing experiences. Annu. Rev. Neurosci. 27, 1-28.

Mehl, M. R., Vazire, S., Ramirez-Esparza, N., Slatcher, R. B., and Pennebaker, J. W. (2007). Are women really more talkative than men? Science 317, 82.

Miura, M. (1993). Individual differences in the perception of facial expression: the relation to sex difference and cognitive mode. Shinrigaku Kenkyu 63,409-413.

Montagne, B., Kessels, R. P., Frigerio, E., De Haan, E. H., and Perrett, D. I.
(2005). Sex differences in the perception of affective facial expressions: do men really lack emotional sensitivity? Cogn. Process. 6, 136-141.

Ortigue, S., Thut, G., Landis, T., and Michel, C. M. (2005). Time-resolved sex differences in language lateralization. Brain 128, E28. [author reply E29].

Ossewaarde, L., Hermans, E. J., Van Wingen, G. A., Kooijman, S. C., Johansson, I. M., Backstrom, T., and Fernandez, G. (2010). Neural mechanisms underlying changes in stresssensitivity across the menstrual cycle. Psychoneuroendocrinology 35, 47-55.

Pedersen, P. M., Jorgensen, H. S., Nakayama, H., Raaschou, H. O., and Olsen, T. S. (1995). Aphasia in acute stroke: incidence, determinants, and recovery. Ann. Neurol. 38, 659-666.

Pellegrini, A. D., and Archer, J. (2005). Sex Differences in Competitive and Aggressive Behavior: A View from Sexual Selection Theory. New York: Guilford.

Plante, E., Schmithorst, V. J., Holland, S. K., and Byars, A. W. (2006). Sex differences in the activation of language cortex during childhood. Neuropsychologia 44, 1210-1221.

Polich, J. (2003). Overview of P3a and P3b Detection of Change: Event Related Potential and Fmri Findings. Boston, MA: Kluwer Academic Press, 83-89.

Pugh, K. R., Shaywitz, B. A., Shaywitz, S. E., Constable, R. T., Skudlarski, P., Fulbright, R. K., Bronen, R. A., Shankweiler, D. P., Katz, L., Fletcher, J. M., and Gore, J. C. (1996). Cerebral organization of component processes in reading. Brain 119(Pt 4), 1221-1238.

Roozendaal, B. (2000). 1999 Curt P. Richter award. Glucocorticoids and the regulation of memory consolidation. Psychoneuroendocrinology 25, 213-238.

Rudick, C. N., and Woolley, C. S. (2001). Estrogen regulates functional inhibition of hippocampal CA1 pyramidal cells in the adult female rat. J. Neurosci. 21, 6532-6543.

Salmelin, R., Schnitzler,A., Parkkonen, L., Biermann, K., Helenius, P., Kiviniemi, K., Kuukka, K., Schmitz, F., and Freund, H. (1999). Native language, gender, and functional organization of the auditory cortex. Proc. Natl. Acad. Sci. U.S.A. 96, 10460-10465.

Sanders, G., and Wenmoth, D. (1998). Verbal and music dichotic listening tasks reveal variations in functional cerebral asymmetry across the menstrual cycle that are phase and task dependent. Neuropsychologia 36, 869-874.

Sandstrom, N. J., and Williams, C. L. (2001). Memory retention is modulated by acute estradiol and progesterone replacement. Behav. Neurosci. 115, 384-393.

Satler, C., Garrido, L. M., Sarmiento, E. P., Leme, S., Conde, C., and Tomaz, C. (2007). Emotional arousal enhances declarative memory in patients with Alzheimer's disease. Acta Neurol. Scand. 116, 355-360.

Schienle, A., Schafer, A., Stark, R., Walter, B., and Vaitl, D. (2005). Gender differences in the processing of disgust- and fear-inducing pictures: an fMRI study. Neuroreport 16, 277-280.

Schirmer, A., and Kotz, S. A. (2003). ERP evidence for a sex-specific Stroop effect in emotional speech. J. Cogn Neurosci. 15, 1135-1148.

Schirmer, A., Kotz, S. A., and Friederici, A. D. (2002). Sex differentiates the role of emotional prosody during word processing. Brain Res. Cogn. Brain Res. 14, 228-233.

Scholten, M. R., Aleman, A., Montagne, B. and Kahn, R. S. (2005). Schizophrenia and processing of facial emotions: sex matters. Schizophr. Res. 78, 61-67.

Shaywitz, B. A., Shaywitz, S. E., Pugh, K. R., Constable, R. T., Skudlarski, P. Fulbright, R. K., Bronen, R. A., Fletcher J. M., Shankweiler, D. P., Katz, L., and Gore, J.C. (1995). Sex differences in the functional organization of the brain for language. Nature 373, 607-609.

Sommer, I.E., Aleman, A., Bouma, A., and Kahn, R. S. (2004). Do women really have more bilateral language representation than men? A meta-analysis of functional imaging studies. Brain 127, 1845-1852.

Sommer, I. E., Aleman, A., Somers, M. Boks, M. P., and Kahn, R. S. (2008) Sex differences in handedness, asymmetry of the planum temporale and functional language lateralization. Brain Res. 1206, 76-88.

Sommer, I. E., Vd Veer, A. J., Wijkstra, J., Boks, M. P., and Kahn, R. S. (2007). Comparing language lateralization in psychotic mania and psychotic depression to schizophrenia; a functiona MRI study. Schizophr. Res. 89, 364-365.

Speck, O., Ernst, T., Braun, J., Koch, C., Miller, E., and Chang, L. (2000) Gender differences in the functional organization of the brain for working memory. Neuroreport 11, 2581-2585.

Tomaz, C., Fran, J. E., and Conde, C. (2003). "Integrative function of the amygdala in emotional memory storage," in Cognition and Emotion in the Brain, eds T. Ono, G. Matsumoto, R. Llinas, R. Norgren, H. Nishijo, and R. Tamura, Amsterdam, 335-346.

Vigil, J. M. (2009). A socio-relational framework of sex differences in the expression of emotion. Behav. Brain Sci.32,375-390. [Discussion 391-428].

Wadnerkar, M. B., Cowell, P. E., and Whiteside, S. P. (2006). Speech across the menstrual cycle: a replication and extension study. Neurosci. Lett. 408, 21-24.

Wardle, M., Cederbaum, K., and De Wit, H. (2011). Quantifying talk: developing reliable measures of verbal productivity. Behav. Res. Methods 43, 168-178. Weiss, E. M., Ragland, J. D., Brensinger, C. M., Bilker,W. B., Deisenhammer,E.A., and Delazer, M. (2006). Sex differences in clustering and switching in verbal fluency tasks. J. Int. Neuropsychol. Soc. 12, 502-509.

Whiteside, S. P., Hanson, A., and Cowell, P.E. (2004). Hormones and temporal components of speech: sex differences and effects of menstrual cyclicity on speech. Neurosci. Lett. 367, 44-47.

Whittle, S., Yucel, M., Yap, M. B., and Allen, N. B. (2011). Sex differences in the neural correlates of emotion: evidence from neuroimaging. Biol. Psychol. 87, 319-333.

Wildgruber, D., Pihan, H., Ackermann, H., Erb, M., and Grodd, W. (2002). Dynamic brain activation during processing of emotional intonation: influence of acoustic parameters, emotional valence, and sex. Neuroimage 15 , 856-869.

Wrase, J., Klein, S., Gruesser, S. M., Hermann, D., Flor, H., Mann, K., Braus, D. F., and Heinz, A. (2003). Gender differences in the processing of standardized emotional visual stimuli in humans: a functional magnetic resonance imaging study. Neurosci. Lett. 348, 41-45.

Yuan, J., Luo, Y., Yan, J. H., Meng, X., Yu, F., and Li, H. (2009). Neural correlates of the females' susceptibility to negative emotions: an insight into gender-related prevalence of affective disturbances. Hum. Brain Mapp. 30, 3676-3686.

Conflict of Interest Statement: The authors declare that the research was conducted in the absence of any commercial or financial relationships that could be construed as a potential conflict of interest.

Received: 11 July 2011; paper pending published: 27 July 2011; accepted: 11 August 2011; published online: 01 September 2011. Citation: Arnone B, Pompili A, Tavares MC and Gasbarri A (2011) Sex-related memory recall and talkativeness for emotional stimuli. Front. Behav. Neurosci. 5:52. doi: 10.3389/fnbeh.2011.00052

Copyright $\odot 2011$ Arnone, Pompili, Tavares and Gasbarri. This is an open-access article subject to a non-exclusive license between the authors and Frontiers Media SA, which permits use, distribution and reproduction in other forums, provided the original authors and source are credited and other Frontiers conditions are complied with. 